\title{
PRESENCE OF RENAL ARTERY VARIATIONS AND ITS SURGICAL CORRELATION
}

\author{
HEMANTH KOMMURU1*, SREE LEKHA D. ${ }^{2}$, JOTHI S.S. ${ }^{1}$, RAJESWARARAO N. ${ }^{1}$ AND SUJATHA N. ${ }^{1}$
}

\author{
${ }^{1}$ Shri Sathya Sai Medical College, Kancheepuram-603 108, TN, India \\ 2Guntur Medical College Kannavari Thota, Guntur-522 004, AP, India \\ *Corresponding Author: Email- hemanth.kommuri@gmail.com
}

Received: June 20, 2012; Accepted: June 27, 2012

\begin{abstract}
The paired renal arteries arise from the aorta just below the origin of the superior mesenteric artery and takes $20 \%$ of cardiac output. These are end arteries with no anastomoses. Variations in the number and arrangement of the renal vessels are extremely common. The so called aberrant or accessory arteries were in fact, normal segmental arteries. The arteries which had proximal origin at the hilum or in the pedicle were probably the result of a variation in the degeneration of the rete arteriosum while those from the aorta were persistent mesonephric arteries. The distal origin of the renal vessels could be explained by the persistence of earlier vessels which were supplying the kidneys when they were in sacral region. In the present study out of 184 kidneys 52 (28.2\%) kidneys showed the presence of additional renal arteries. Out of 52 kidneys 34 kidneys had one additional artery, 18 kidneys had two additional arteries. The results are statistically significant. The presence of additional renal arteries was found unilaterally in 6 cadavers and bilaterally in 20 cadavers. In 23 kidneys additional artery towards the superior pole (Superior polar artery) was observed and in 29 kidneys inferior polar arteries were seen. With the increase in number of cases of kidney transplantation, living donar grafts have become major source for maintaining the donor pool, and the successful allograft with multiple arteries had become a necessity. Variations in the origin and course of the renal arteries occur frequently and are of special interest to the urologist with respect to the disease associated with it. Multi Detector Computer Tomography (MDCT), angiography and arteriography should be performed prior to every nephrectomy. It become's mandatory for the surgeon to understand the abnormality or variations in the renal vasculature .
\end{abstract}

Keywords- Accessory renal arteries, Superior polar arteries, Inferior polar arteries, Segmental arteries

Citation: Hemanth Kommuru, et al. (2012) Presence of Renal Artery Variations and Its Surgical Correlation. International Journal of Medical and Clinical Research, ISSN:0976-5530 \& E-ISSN:0976-5549, Volume 3, Issue 5, pp.-176-179.

Copyright: Copyright@2012 Hemanth Kommuru, et al. This is an open-access article distributed under the terms of the Creative Commons Attribution License, which permits unrestricted use, distribution and reproduction in any medium, provided the original author and source are credited.

\section{Introduction}

The paired renal arteries arise from the aorta just below the origin of the superior mesenteric artery and takes $20 \%$ of cardiac output. These are end arteries with no anastomoses. Variations in the number and arrangement of the renal vessels are extremely common. The so called aberrant or accessory arteries were in fact, normal segmental arteries. As the invasive interventions such as renal transplantation, interventional radiologic procedures and urologic operations increase, awareness of the possible variations of the renal arteries is necessary for adequate surgical management in the aforementioned specialties.

\begin{abstract}
Embryology
The proximal origin of the segmental arteries of the kidney could be explained by reference to the account of their development given by Felix [1]. The mesonephric arteries extended from the $6^{\text {th }}$ cervical to the $3^{\text {rd }}$ lumbar segments. The cranial ones disappear. The caudal arteries form the rete arteriosum urogenitale. The arteries which had proximal origin at the hilum or in the pedicle were probably the result of a variation in the degeneration of the rete arteriosum while those from the aorta were persistent mesonephric arteries. The kidney developed originally in the region of the first sacral vertebra and due to change in the curvature it trav-
\end{abstract}


elled up about 4 or 5 segments. During its migration upwards the kidney had blood supply from the regional arteries. The earlier ones were dropped as it reached its final position. The distal origin of the renal vessels could be explained by the persistence of these earlier vessels.

\section{Materials and Methods}

The arterial supply to the kidneys of 92 cadavers of both sexes, aged 40-60 years, was studied over a period of 5 years. By careful dissection the arteries entering the kidneys were traced to observe the pattern of branching.

\section{Results and Observations}

In the present study out of 184 kidneys 52 kidneys showed the presence of accessory renal arteries. Out of 52 kidneys 34 kidneys had one additional artery, 18 kidneys had two additional arteries $(p=0.01)$. (Fig. 1, Fig. 5). The results are statistically significant. The presences of additional renal arteries were found unilaterally in 6 cadavers (Fig. 3) and bilaterally in 20 cadavers (Fig. 7).

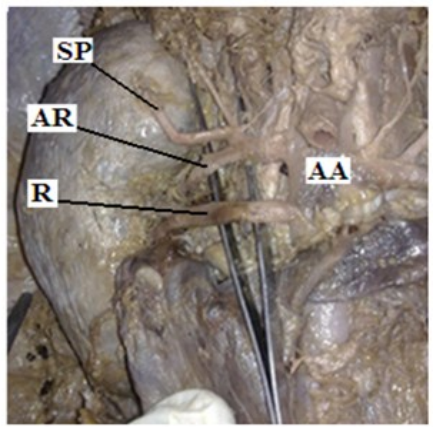

Fig. 1- One accessory renal artery arising from the Abdominal Aorta from that one superior polar artery towards the superior pole of the right kidney

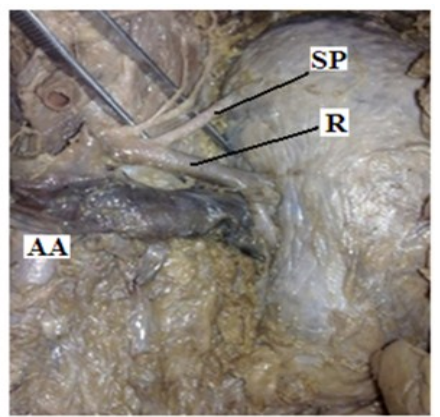

Fig. 2- Superior polar artery arising from the renal artery on the left side kidney

Prehilar multiple branches were directed towards the apical, superior, middle, posterior and inferior segments of the kidney. In 23 kidneys additional artery towards the superior pole (Superior polar artery) was observed (Fig. 2) and in 29 kidneys inferior polar arteries were seen (Fig. 7). In 11 cases along with superior and inferior polar arteries additional arteries were seen entering the hilum of the kidneys (Fig. 6). In one cadaver polycystic kidney was present along with additional renal artery (Fig. 3). In one cadaver additional renal artery was coming from the superior mesenteric artery to supply the left kidey (Fig. 4).

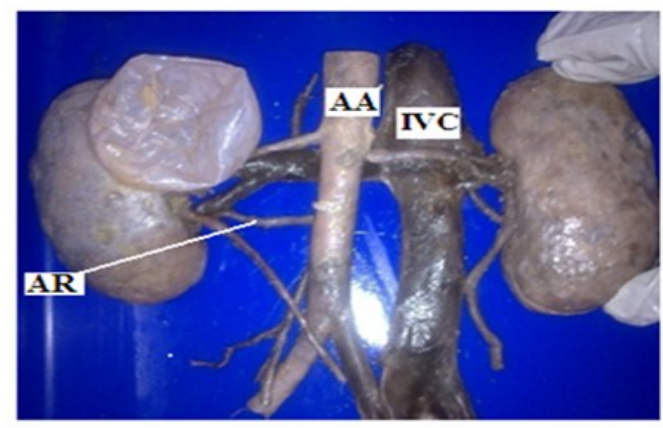

Fig. 3- Posterior view of polycystic kineys showing a accessory renal artery on left side arising from the abdominal aorta entering the lower aspect of the hilum

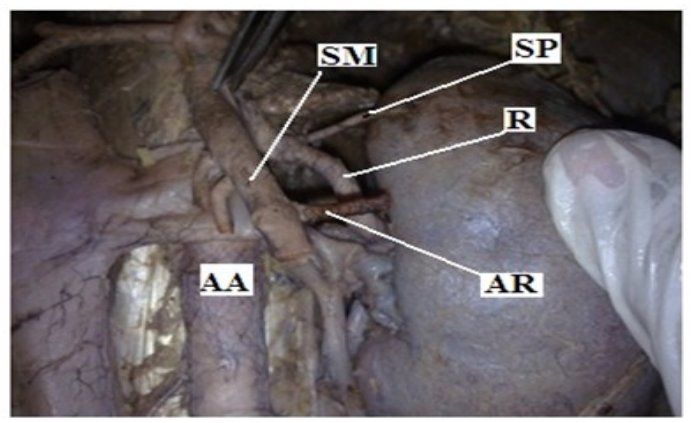

Fig. 4- Left kidney showing two superior polar arteries arteries arising from the renal artery and superior mesenteric artery

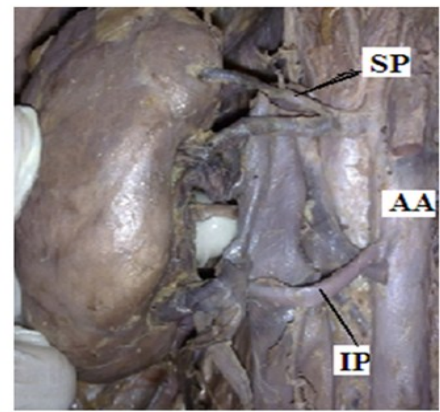

Fig. 5- From the abdominal aorta two renal arteries were arising, one artery is dividing into two branches going superior aspect of the hilum and superior pole of the kidney, another branche going towards the inferior pole

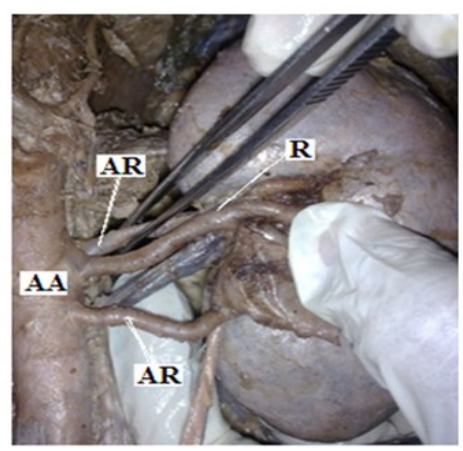

Fig. 6- From the abdominal aorta 3 renal arteries were arising in that one is going towards the hilum one was going towards the aspect of the hilum one is going towards the lower pole passing anterior to the starting point of the ureter 


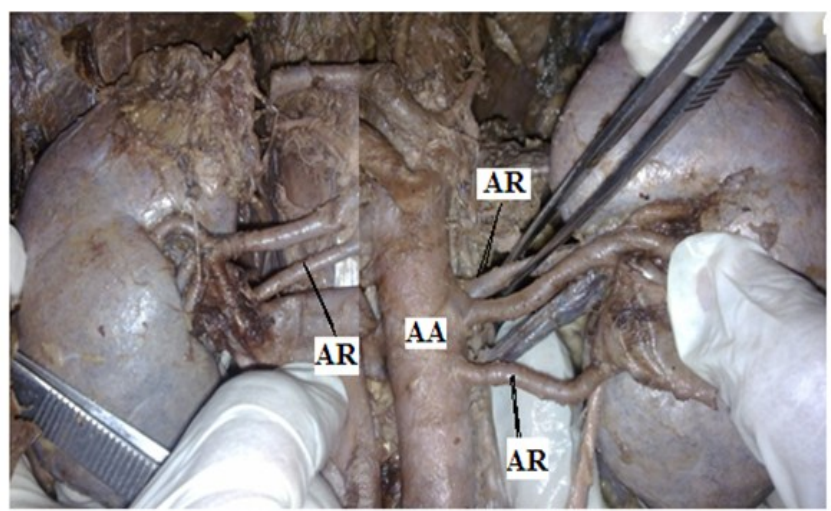

Fig. 7- In one cadaver showing additional renal arteries both on the sides

\section{Presence of Additional arteries in kidneys}

= 1 Additional artery = 2 Additional arteries

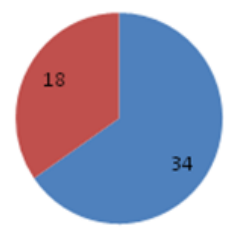

Fig. 8- Pie diagram showing the one Additional artery and Two Additional arteries

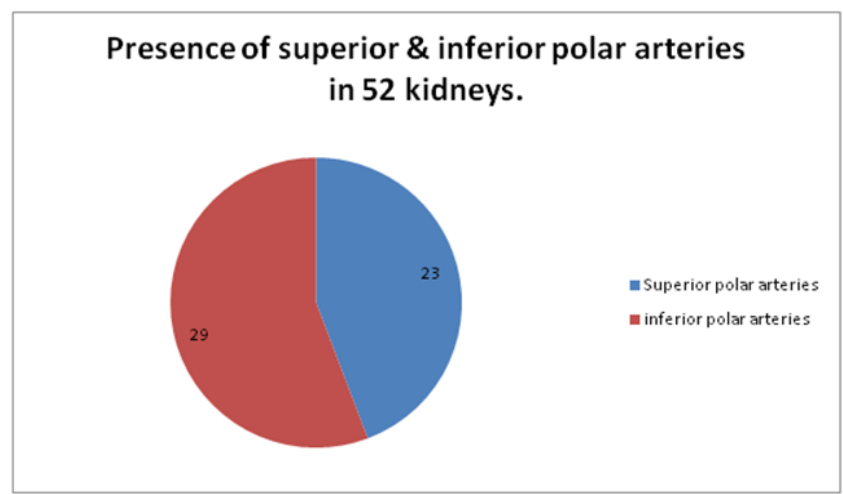

Fig. 9- Pie diagram showing presence of superior and inferior polar arteries

\section{Discussion}

The renal vascular segmentation was discovered by John Hunter in 1794, but a detailed account was given in 1950's by corrosion cast studies. There are five defined arterial segments; apical, superior, middle, inferior and posterior. The anatomical knowledge of these segments is important while performing nephrectomies [2].

The incidence of accessory renal arteries had been variously reported as 50\% (Helstrom) [3] 25\% (Edsman) [4] and 30\% (HenryGray) [5]. In the present study the incidence of accessory renal arteries was $28.2 \%$.
Saldarriaga B., et al [6] reported ninety seven (24.9\%) out of 390 kidneys having additional arteries. 87 had one additional artery $(22.3 \%) 10$ had two additional arteries (2.6\%). The frequency of one additional artery was $43.5 \%$ on right side and $56.3 \%$ on left side. Tarzamni M.K., et al [7] observed 117 cases- in that 76 were males $(65 \%)$ \& 41 were femlaes (35\%). An accessory artery was present in 58 kidneys (24.7\%) \& significantly more often occurred on the right side than on the left side( 38 of right kidneys, 20 of left kidneys).

In our study 52(28.2\%) kidneys out of 184 kidneys had additional arteries. 34 had one additional artery (18.5\%), 18 kidneys had two additional arteries (9.7\%). The frequency of one additional artery was $32.3 \%$ on the right side and $67.7 \%$ on the left side. The frequency of two additional arteries was $50 \%$ on the right side and $50 \%$ on the left side.

In addition Satyapal, et al [8] presented these findings- Single additional artery were more common on the left side (27.6\%) than the right side (18.6\%). Second additional arteries occurred with similar incidence on either side (right 4.7\%; left 4.4\%). In our study also the presence of single additional artery was more common on left side than on the right side. Second additional arteries occurred with similar incidence on either side.

According to Weinstein, Counters and Derbes [9] the incidence of accessory arteries passing to the lower pole was approximately twice that passing to the upper pole and similar figures were recorded by Albarran [10]. In our study the incidence of arteries passing to the lower pole was more than that of the superior polar arteries.

According Budhiraja V. [11] the Superior Polar arteries were found in $22.6 \%$. In our study the presence of Superior polar artery was found in $25 \%$ cases \& inferior polar artery in $31.5 \%$ cases and more on the left side.

Anomalous vessels occurred unilaterally 3 times as often as bilaterally and were more frequent on the left side and in females. According to Banowsky [12] unilateral multiple renal arteries occur in approximately $23 \%$ of the population. Another $10 \%$ have bilateral multiple arteries. In the present study the accessory renal arteries were present unilaterally in 6 cadavers forming $6.5 \%$ and bilaterally in 20 cadavers forming $21.7 \%$ and was more in males.

Presence of variations of renal arteries may be associated with other underlying renal pathological conditions Das S. [13]. In our study in one cadaver polycystic kidneys were present and in the other unilateral bifid ureter was observed.

\section{Conclusion}

With the increase in the number of cases of kidney transplantation, living donar grafts have become major source for maintaining the donor pool, and the successful allograft with multiple arteries had become a necessity. Variations in the origin and course of the renal arteries occur frequently and are of special interest to the urologist with respect to the diseases associated with it. The relevance of the aberrant arteries in systemic hypertension and uretral obstruction was established. With the advent of laparoscopic renal surgeries and donor nephrectomies, allograft with multiple renal arteries can be implanted with short and long term results comparable to those with single renal arteries by using surgical techniques that best fits a particular situation. Multi Detector Computer Tomography (MDCT), angiography and arteriography should be 
performed prior to every nephrectomy. It becomes mandatory for the surgeon to understand the abnormality or variation in the renal vasculature. Otherwise renal transplant may be jeopardized by the presence of aberrant vessels. Therefore considering the increase in the incidence of the accessory and multiple renal arteries with the anatomical knowledge of such may be important for academic, surgical as well as radiological procedures.

\section{Abbreviations}

- AA- Abdominal Aorta

- AR-Accessory Renal Artery

- IVC- Inferior Venacava

- R- Renal Artery

- SM- Superior Mesenteric Artery

- SP-Superior Polar Artery

\section{References}

[1] Felix W.M. (1912) Manual of human embryology, Keibel and Mall, II, 833.

[2] Shakeri Ab., Tubbbs Rs., Shoja M.M., Pezeshk P., Farahani Rm., Khaki A.A., Ezzati F., Seyednejad F. (2007) Surg. Radiol. Anat., 29(1), 89-92.

[3] Helstrom J. (1927) Act. Chis. Scand. 61, 289 -330.

[4] Edsman G. (1954) Acta. Radiol. Stockh., 42 26-32.

[5] Gray's anatomy (2005) The anatomical basis of clinical practice, 39th edition, 1274.

[6] Saldarriaga B., Perez A.F., Ballesteros L.E. (2008) A direct anatomical study of additional renal arteries in a Colombian mestizo population, 67(2), 129-13.

[7] Tarzamni M.K., Nezami N., Rashid R.J. (2008) Folia Morphol (Warsz), 67(2), 104-10.

[8] Satyapal K.S., Haffejee A.A., Singh B., Ramsroop L., Robbs J.V., Kalideen J.M. (2001) Surg. Radiol. Anat., 23, 33-38.

[9] Weinstein B.B., Countess E.H. and Derbes V.J. (1940) Urol. Cutan. Rev., 44, 137-139.

[10]Albarran J. (1909) Medicine operatiore des voies urinouris, 4.

[11]Budhiraja V., Rastogi R., Asthana A.K. (2011) Folia Morphol (warsz)., 70(1), 24-8.

[12]Banowsky L.H.W. (1989) Stewart's operative urology (2nd edt) Baltimore, Williams and Wilkins.

[13]Das S. (2008) Bratisl. Lek. Listy., 109, 182-184. 